\title{
University Network Engineering Professional Teaching Model
}

\author{
Han You-qian ${ }^{1, a}$, Xuxiu ${ }^{2, a}$
}

Dept. of China mining university college of computer science and technology(CUMT),

Jiangsu Xuzhou, 221116

(xuxiu@cumt.edu.cn)

Keywords: Network engineering.Network practice.Teaching mode.Teaching reform

\begin{abstract}
Network engineering is the field of emerging technologies, and how to better provide the community with the talents currently on network engineering teaching mode design became the primary task to meet the requirements of the close combination of computer technology and communication technology. In this article from the goal to cultivate and improve students' ability to network engineering practice, in terms of network engineering curriculum reform, network engineering lab environment construction explore new era network engineering professional teaching reform ideas to improve students by enhancing the practical teaching links engineering capability and innovative quality of network engineering professionals.
\end{abstract}

\section{Introduction}

Development of computer technology, let us feel the digital age brings the convenience, based on the master computer technology and communication technology on the basis of network technology is more rapid development and application of up. Especially network hardware transmission medium, the communication protocol, the network operating system, Internet technology, etc. Along with the popularization of the network technology, and social needs of the increasingly growing, making many college computer network as the computer technology of an independent professional direction, and increase the many and the network related professional course, in order to cultivate and network technology excellent related network talents.

\section{College Network Engineering Professional Teaching Situation}

Relative to the rapid development, content updated quickly, strong applicability, but teaching history is relatively short, experience less network engineering technology and theory, inevitably produce a series of problems. Although many universities in the network engineering talent training scheme, professional curriculum system, practice teaching system, and many other aspects of the research and practice. But in current college network engineering professional training and teaching kind has shown the following questions:

1.Experiment condition cannot reach and practical teaching matching software and hardware environment requirements Network engineering teaching practice need to provide a large number of hardware laboratory equipment, and the equipment cost is high, the replacement cycle is short. The huge expenditure which many universities can only slow replacement cycle, or make people common laboratory equipment. This will lead to the students' practical and social technology demands or cannot reach the approved amount of status.

2. The lack of systematic and engineering thinking mode

College teachers and lab personnel are mostly born regular professional training, its itself is the lack of practical engineering experience, specialized training link relatively insufficient. So will result in not to provide students with engineering, systematic study and practice instruction, which has caused by lack of guidance, Combined with students' learning and training are mostly depend on the book knowledge, contact engineering equipment and the environment is very little chance, this has caused the condition of engineering consciousness, there is actual the overhand ability is weak, not enough to meet the social needs of the present situation. 


\section{The NetworEngineering Teaching Mode}

\section{"Work Along Both Lines" Teaching Mode And Principle}

The so-called work along both lines teaching mode, namely the theory and practice of two aspects at the same time the attention of the teaching mode. Is the theoretical teaching content and laboratory content organically fuses in together, not according to the conventional textbooks traditional teaching, to break the limit of theory and experiment. The course will be theory teaching, practice teaching, production and technical service into a whole. Teaching link is relatively concentrated, strengthen the laboratory in teaching activities. Teachers and students with double active teaching interaction is given priority to. Alternation of theory and practice. The reason is real, real right in, highlight the student beginning ability and professional skills training, and fully mobilize and motivate students' interest in learning is a kind of teaching method. "Both" teaching principles embody the following aspects:

1. To the practical work for the teaching task based on. Around the work task determine objective, select the course content, make professional teaching plan, construction work, with study course system. For students to build the good study architecture.

2. To develop comprehensive practical ability as the goal. Course orientation and direction, course content and requirement, teaching process and appraisal and so on, all want to highlight the students' comprehensive vocational ability training, pay attention to training students' professional ability, method ability and social ability.

3. The students give priority to. An effective to promote students' autonomous learning and self management of the teaching mode and evaluation model, outstanding in order to apply it.

\section{Network Engineering Curriculum Teaching Improvement Measures}

Network project is in recent years that it has set new course, majored in computer is an important professional required course, has the very strong practicality. In the teaching content and network technology, Linux operating system, network cabling, switching and routing technology, computer network principle, information and network security, and other professional course has many connections, so network project this new course in the teaching syllabus formulation, the use of teaching materials, teaching methods and means, professional laboratory construction, etc, and at the same time, need to reform requires teachers to have rich computer network engineering practical experience.

1. Implementation, project acceptance, network transformation and optimization, network maintenance work link, through the actual combat to improve the teachers' practical ability, really will theory and practice organically, and will of the actual project cases applied to the curriculum teaching process, outstanding course practicality and practical, improve the teaching quality, arousing students' interest in study.

2. The teaching content reform

Teaching material is the main basis of teaching, teaching content is to describe the special books, is the embodiment of the syllabus, teaching material construction is the core of the course construction and teaching work, is stable teaching order and improve the teaching quality of the important guarantee. Network engineering teaching of higher education must be based on training target, to break the traditional teaching structure, from the computer network engineering, based on example derivation concept, based on the actual case in the application of network engineering as the main line, with the popular concise language to clarify the connotation and essence of the concept, improve the teaching material's practical. And the existing network engineering materials and networking technology curriculum teaching material is similar, we according to the actual situation should be organization we have a project experience the teacher, by strengthening the cooperation between colleges and enterprises, according to the syllabus to write new teaching material.

\section{Teaching content reform}

In order to adapt to the computer network of new technology, new concepts, new applications are constantly emerging and rapid development, need timely modify teaching outline, the introduction of all kinds of new technology in the practical application of the network project, the 
project management model, to the nearest principle, according to the grouping for class discussion, discuss the results in the classroom by the group representatives to report, to avoid the abstract theoretical study, improve the quality of teaching. Design heuristic autonomous learning task, so that the students can actively tracking network project of the latest developments in technology, training students' independent learning ability, and guide students to understand each manufacturer equipment parameters and function, students are required to provide solutions, to regulate the network engineering document writing, the network design train of thought, the follow-up to lay the foundation of classroom teaching activities, improve the students' independent thinking and innovation ability.

4.The teaching method reform

The multimedia information technology applied in teaching, bring the change of teaching method, network engineering complex abstract concepts through the sound, the animation demonstration way, make the abstract theory visualization, complicated process simplification, deepen the students' understanding of the teaching content. All kinds of network engineering theory, the complicated network model and the working process, should be in real life to find appropriate examples. But requires teachers to have rich experience in teaching, accumulate a large amount of real life case for simulation, helps the student to intuitive, image understanding and master the theoretical knowledge of network engineering, arouses student's enthusiasm.

\section{The Construction Of Network Engineering Practice}

\section{To Strengthen The Network Laboratory Construction}

Network engineering experimental teaching can not only limited to verify book knowledge, according to the theory teaching needs gradual open application, comprehensive and innovative experiments, in order to cultivate students' basic skills at the same time, add advanced comprehensive experiment content, the verification demonstration model experiment and comprehensive research experiment combined, make the student to the knowledge to digest, training students' independent find and solve problems of the comprehensive quality. Strengthen the network cabling, network service application, routing exchange, wireless network, network security management of the laboratory construction, in order to meet the normal teaching needs.

\section{Outside Strengthen Training Base Construction}

According to the future market professionals demand change, emphasizing professional practice ability of the network engineering course must take the social demand and employment as the guide, pay attention to the network technology development, explore new features and personalized training program, the Open University is the future direction of change, cooperation education mode is to cultivate innovative talents, the effective education way. The school-enterprise cooperation is to train higher technology applied talents only, the school is concerned, training high level applied technology talents, only rely on the school resources and environment is difficult to achieve. Train higher technology applied talents must have with modern production technology and equipment and operation environment of modern enterprise support, to adapt to the rapid development of network technology.

In the practice teaching to find a modern network engineering enterprises practice is very important, practice base outside the basic task is to cultivate students' project practice ability. Students in the practice base by understanding the organization of enterprise production process, process, the theoretical knowledge they learned in class in the practical work, the application of the theory deeply understand and grasp the principle known. Through the real industrial environment practice, the students' engineering quality of the training, has the irreplaceable role, and can make up for the school internal laboratory in the engineering practice of the insufficiency of the environment for high level network engineering talents to create the necessary practice teaching conditions.

\section{"Joint Cisco" Teaching Mode}

The current network engineering teaching and practice system, into the cisco network technology college related elements is rich students' learning resources, to improve students' practical ability, 
cultivate students' learning interest, open field of vision of students' specialty effective way. Combined with cisco network technology, knowledge system provide online evaluation and feedback system, for students to create a good learning atmosphere, after class To cisco network technology, knowledge system of practice teaching ideas and methods for reference, to improve the practice teaching effect, training and training students' engineering consciousness; Cisco network technology, knowledge system while at the same time emphasizing the real environment and equipment operation, according to every kind of course are put forward the corresponding equipment and environment configuration requirements, formulate the relevant norms and articles of association; Attract and digestive cisco network technology, knowledge system of teaching concept, in the teaching process of abundant multimedia technology, active classroom atmosphere, the use of interactive way, is the student in the open operation in the process of understanding and mastery of the content. To deepen the understanding of the content of what they have learned and apply.

\section{The Network Engineering Practice Tteaching Virtualization}

According to research it is not difficult to find that, using the simulation software to carry on the practice teaching of virtualization for network engineering professional teaching is very important. We can use the simulation software has the NS2, OPNET, packet tracer, etc. Using the simulation software can not only demonstrate the working principle of layer, and by our own modification agreement parameters to improve agreement and verification, also can simulate network topology and some network equipment work performance.

But through the "virtual project teaching method" in the computer network engineering practical application cases, using Packet Tracer 5.3 free simulation software, such as design, command configuration, system debugging, so can make each student realize how to realize network equipment, application layer of the communication between the relevant application access process, as on a PC through the Internet device access remote a server of the HTTP service, simulate the similar and real scene, greatly improving the learning interest of the students, the computer network engineering understanding more deeply. Such as using Packet Tracer routing table to realize the router configuration.

Software Packet Tracer can through the "configure" configuration window to terminal equipment or switching equipment to do some basic configuration. Such as IP address, static routing, dynamic routing, etc., can also use IOS command set window to exchange equipment parameter configuration, through the window to the user to be able to be familiar with switch, router's function and its basic configuration command to use.

\section{Conclusion}

Network engineering in the integration of teaching, scientific research, on the basis of practice, will be more conducive to the cultivation of network knowledge and abstract thinking ability and computer network hardware and software basic theory and technology, computer network information security applications, computer network management and maintenance, network system design and development and integration of high-level network engineering application technology and scientific research personnel. According to the computer science and technology development situation, in-depth teaching practice, put some new products, new technology, new ideas are put into network engineering experiments, the experimental teaching into the classroom and began to tell the two parts. Combination of theory and practice closely, let the theory guiding the experiment, the experiment to verify the theory. Not only deepened the student to the computer network theory, curriculum theory understanding and consolidate, also enlarged the scope of knowledge and improve the students to network design and analysis skills.

\section{References}


[1] XingMin, HuangLan. Computer simulation teaching research and practice of modern education science: thanks. Higher education research, 2007, (1) : 152153.

[2] Dong pay countries. The Ns2 simulation technology in the application of computer network experiment teaching and research. Computer education, 2005. (1 o) : 5 l a 53.

[3] WenWei. Based on zero pnet network optimization [J]. Journal of jiangxi university of science and technology, 2008.

[4] HuangSheng fierce, HuangYi. Constructing a "network protocol simulation teaching system" platform research thanks. Laboratory research and exploration, 2006, (2) : 117118.

[5] XiaoYuanE Packet Tracer. HuangXiaoYan in computer network teaching towel application [J]. Journal of the jinggang mountains, 2009 (2) : - 57.87.

[6] LiJinDuo LiuHongBo. WangYongBin etc. Based on virtual reality remote teaching platform research and design [J].journal of micro computer information, 2006 (36) : 257300-302.

[7] FengMaoYan ZhaiHongQun. Higher vocational computer network professional personnel training to explore [J].journal of wuxi vocational and technical college journal, 2010 (2) : - 17.

[8] Creek leah. Applied university computer network curriculum teaching reform [J].journal of value engineering, 2010, 29 (22) : 207-208.

[9] Meadors t. computer network practical tutorial laboratory manual [M]. Beijing: mechanical industry press, 2000.

[10] WangYanLi. Yin wai rich. Computer network engineering experiment explore optimization [J].journal of modern electronic technology. 2008 (13) : 175-176.179.

[11] XingMin. Computer simulation technology in network protocol experiment teaching. The application [J]. Journal of engineering technology in jilin normal university. 2008 (12) : 98-100. 